[Agr. Biol. Chem., Vol. 30, No. 11, p. 1069 1075, 1966]

\title{
Studies on Biosynthesis of Biotin by Microorganisms
}

\author{
Part V. Degradation of Desthiobiotin by Molds*
}

\author{
By Shojiro Iwahara, ${ }^{* *}$ Seigo Takasawa, ${ }^{* * *}$ Tatsurokuro Tochikura \\ and Koichi Ogata
}

Department of Agricultural Chemistry, Faculty of Agriculture, Kyoto University, Kyoto

Received March 24, 1966

\begin{abstract}
During the course of the study on the production of biotin from desthiobiotin by microorganisms, the present authors have found that some strains of molds produced an unknown biotin-vitamer (BS-factor) from desthiobiotin. The present investigation was undertaken to clarify the characteristics of the unknown vitamer. The unknown vitamer produced from desthiobiotin was isolated in crystalline form from culture filtrate of Aspergillus oryzae. The compound isolated was identified as 4-methyl-5-( $\omega$-carboxybutyl)imidazolidone- 2 by the physico-chemical procedures.
\end{abstract}

\section{INTRODUCTION}

In the previous paper of this series, ${ }^{11}$ the authors demonstrated that various kinds of microorganisms produced a large amount of biotin from desthiobiotin.

During the study on the production of biotin from desthiobiotin by various molds, the present authors have found that some molds produced a large amount of an unknown biotin-vitamer from desthiobiotin. The vitamer well supported the growth of Bacillus subtilis, but hardly the growth of Saccharomyces cerevisiae, Neurospora crassa and Lactobacillus arabinosus. The vitamer was tentatively named as "BS-factor" (Bacillus subtilis factor).

Little is known about the metabolic fate of biotin and desthiobiotin in microorganisms. Recently, it has been reported by several

* This paper was presented at the 211 th Meeting of Kansai Division of Agricultural Chemical Society of Japan held on September 19, 1964, at Kyoto.

** Present address, Department of Agricultural Chemistry, Faculty of Agriculture, Kagawa University, Miki-cho, Kagawa-ken.

*** Present address, Tokyo Research Laboratory, Kyowa Hakko Kogyo Co., Ltd., Tokyo.

1) S. Iwahara, S. Takasawa, T. Tochikura and K. Ogata, This Journal, 3o, 385 (1966). workers $^{2 \sim 4}$ that biotin was decomposed by the enzyme preparations of some microorganisms and animal tissues, and the results that ${ }^{14} \mathrm{CO}_{2}$ was released from biotin- ${ }^{14} \mathrm{COOH}$ during the incubation with the enzyme preparations suggest that the side chain of biotin is decomposed by the reaction such as $\beta$-oxidation. However, the chemical characteristics of the decomposed products have not been well known.

The present investigation was undertaken to clarify the characteristics of the unknown biotin-vitamer which was assumed to be a decomposed product of desthiobiotin. The results showed that desthiobiotin was converted to BS-factor by various molds during the cultivation, and the vitamer produced from desthiobiotin by Aspergillus oryzae was isolated in crystalline form from the culture filtrate. The compound isolated was identified as 4methyl-5-( $\omega$-carboxybutyl)-imidazolidone- 2 by

2) R.M. Baxter and J.H. Quastel, J. Biol. Chem., 201, 751 (153).

3) J.E. Christner, M. J. Schlesinger and M. J. Coon, ibid., 239, 3997 (1964).

4) R. N. Brady, Lan-Fun Li, D. B. McCormik and L.D. Wright, Biochem. Biophys. Res. Comm., 19, 777 (1965). 
physico-chemical analyses. Some microbiological and chromatographic properties of the compound are also presented.

\section{MATERIALS AND METHODS}

Microorganisms and Culture Method. The molds used in the present study had been preserved in our laboratory. The following medium was used; glucose, $50 \mathrm{~g} ; \mathrm{NaNO}_{3}, 9 \mathrm{~g} ; \mathrm{KH}_{2} \mathrm{PO}_{4}, 0.5 \mathrm{~g} ; \mathrm{K}_{2} \mathrm{HPO}_{4}, 0.5 \mathrm{~g}$; $\mathrm{NaCl}, 0.5 \mathrm{~g}$; metal ions $\left(\mathrm{FeCl}_{3}, 1 \mathrm{mg} ; \mathrm{ZnSO}_{4} \cdot 7 \mathrm{H}_{2} \mathrm{O}\right.$, $\left.1 \mathrm{mg} ; \mathrm{MnSO}_{4}, 1 \mathrm{mg} ; \mathrm{CuSO}_{4} \cdot 5 \mathrm{H}_{2} \mathrm{O}, 0.1 \mathrm{mg}\right) ; d, l-$ desthiobiotin, 10 to $1000 \mathrm{mg}$; in $1000 \mathrm{ml}$ of tap water. The $\mathrm{pH}$ was adjusted to 6.8 .

Five $\mathrm{ml}$ of the medium was taken into test tubes $(23 \mathrm{~mm} \times 200 \mathrm{~mm})$. The test tubes were incubated for 3 to 10 days at $28^{\circ} \mathrm{C}$ on a shaker ( 340 reciprocations per minute). After the growth, the mycelial mats were removed by filtration through the filter paper and the filtrates were subjected to the following analysis.

Determination of Biotin-Vitamers. True biotin was quantitatively determined by microbiological assay with Lactobacillus arabinosus according to the method of Wright and Skeggs.5) Total biotin was determined by microbiologicol assays with Saccharomyces cerevisiae according to the method of Snell et al.6) and with Neurospora crassa according to the method of Horowitz and Beadle.7) A biotin-requiring strain of Bacillus subtilis isolated from "Natto" in our laboratory was also used for microbiological assay of biotin-vitamers by the turbidity measurement. Microbiological assay of biotin-vitamers with Bacillus subtilis was carried out by the following procedure; the spore suspension of the microorganism was heated at $80^{\circ} \mathrm{C}$ for 10 minutes to kill the vegetative cells and washed three times with the sterilized sodium chloride solution of 0.85 per cent. One drop of this spore suspension (optical density at $610 \mathrm{~m} \mu$ was about 0.3 ) was inoculated into the test tubes $(16.5 \mathrm{~mm} \times 160 \mathrm{~mm})$ containing $4 \mathrm{ml}$ of the medium supplemented with the standard series of biotin and the samples. The medium used had the same components as that used for the microbiological assay with Lactobacillus arabinosus. 5) The microorganism was grown for 14 to 18 hours at $28^{\circ} \mathrm{C}$ on a shaker (280 reciprocations per minute), then the

5) L. D. Wright and H. R. Skeggs, Proc. Soc. Exptl. Biol. Med., 56, 95 (1944).

6) E. E. Snell, R. E. Eakin and R.J., Williams, J. Am. Chem. Soc., 62, 175 (1940).

7) N.H. Horowitz, and G.W. Beadle, J. Biol. Chem., 150,

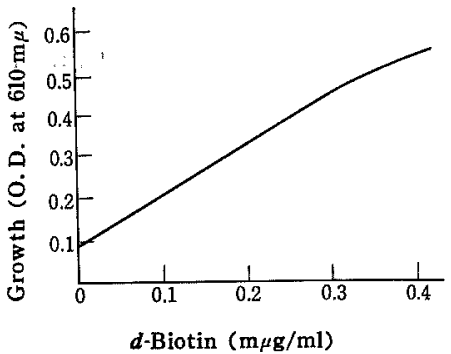

FIG. 1. Typical Standart Curve of the Bioassay with Bacillus subtilis.

bacterial turbidity was measured. Typical standard curve is shown in Fig. 1. This microorganism utilized desthiobiotin, 7,8-diaminopelargonic acid, 7-keto-8aminopelargonic acid, biotin- $d$-sulfoxide and unknownvitamer (BS-factor) instead of biotin, but did not utilize pimelic acid. The amount of BS-factor was tentatively determined by the subtraction of the values assayed with yeast from those with Bacillus subtilis. The amount of all biotin-vitamers was presented as biotin.

Column Chromatography of Biotin-Vitamers. Separation of biotin-vitamers was carried out by the ion-exchange column chromatography according to the method described in the previous paper. ${ }^{8}$

Paper Chromatography and Paper Electrophoresis. Ascending paper chromatography was carried out on Tôyô Roshi No. 53 filter paper with nbutanol-acetic acid-water ( $4: 1: 1), n$-butanol-1 N HCl (6:1), $n$-butanol (satd. with water) and phenol-water $(4: 1)$ as the developing solvents.

Paper electrophoresis was performed on Tôyô Roshi No. 53 filter paper at 300 volts for 4 hours. The following buffer solutions were used at a final concentration of $0.025 \mathrm{M}$; bipotassium phthalate buffer, $\mathrm{pH} 2$ to 6 , and potassium phosphate buffer, $\mathrm{pH} 7$ and 8.

Detection of the biotin-vitamers on the chromatograms was carried out by the bioautographic technique reported in the previous paper. ${ }^{8)}$

\section{RESULTS AND DISCUSSION}

Production of BS-Factor from Desthiobiotin by Various Molds

During the course of study on the produc-

8) K. Ogata, T. Tochikura. S. Iwahara, K. Ikushima, S, Takasawa, M. Kikuchi and A. Nishimura, This Journal, 29, 895 (1965). 
tion of biotin from desthiobiotin by various kinds of molds, it was found that an unknown

TABle I. PRODUCTION OF BS-FACTOR FROM DESTHIOBIOTIN BY VARIOUS MOLDS

\begin{tabular}{|c|c|c|c|}
\hline \multirow[t]{3}{*}{ Molds tested } & \multicolumn{2}{|c|}{$\begin{array}{c}\text { Amount of biotin- } \\
\text { vitamers assayed } \\
\text { with }\end{array}$} & \multirow{2}{*}{$\begin{array}{l}\text { BS-factor } \\
\text { produced } \\
(B)-(A)\end{array}$} \\
\hline & 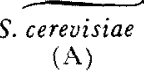 & $\begin{array}{l}\text { B. subtilis } \\
\text { (B) }\end{array}$ & \\
\hline & $\mu \mathrm{g} / \mathrm{ml}$ & $\mu \mathrm{g} / \mathrm{ml}$ & $\mu \mathrm{g} / \mathrm{ml}$ \\
\hline Rhizopus chinensis & 10 & 20 & 10 \\
\hline Aspergillus oryzae & 0.2 & 40 & 39.8 \\
\hline Fusarium culmorum & 25 & 60 & 35 \\
\hline Penicillium purpurogenum & 5 & 50 & 45 \\
\hline Penicillium oxalicum & 0.2 & 30 & 29.8 \\
\hline $\mathrm{H}-28 *$ & 30 & 50 & 20 \\
\hline H-74* & 20 & 50 & 30 \\
\hline
\end{tabular}

* Aspergillus sp. isolated from soil. The molds were cultivated on the medium containing $100 \mu \mathrm{g}$ of $d l$-desthiobiotin per $\mathrm{ml}$ for 7 days on a shaker. biotin-vitamer (BS-factor) was produced together with a small amount of biotin in the culture filtrates of some molds when they were cultivated for longer days ( 5 to 7 days). As shown in Table $I$, it was found that some molds produced a large amount of BS-factor from desthiobiotin. The data suggest that desthiobiotin added to the medium was mainly converted to the BS-factor, although a small amount of true biotin was produced.

\section{Influence of Nitrogen Sources and Metal Ions on the Production of Biotin and BS-Factor from Desthiobiotin by Aspergillus oryzae}

The influences of nitrogen sources and metal ions on the production of biotin and BS-factor from desthiobiotin by Aspergillus oryzae were investigated. As shown in Table II, when urea, sodium nitrate or casamino acid was used as a nitrogen source without addition of

Table II. Effect of Nitrogen Sources and Metal ions on the Production of Biotin and BS-FACTOR FROM DESTHIOBIOTIN

\begin{tabular}{|c|c|c|c|c|c|c|c|}
\hline \multirow[b]{2}{*}{$\begin{array}{l}\text { Nitrogen } \\
\text { source }\end{array}$} & \multirow{2}{*}{$\begin{array}{c}d l \text {-Desthio- } \\
\text { biotin } \\
(20 \mu \mathrm{g} / \mathrm{ml})\end{array}$} & \multirow{2}{*}{$\begin{array}{l}\text { Metal } \\
\text { ions* }\end{array}$} & \multicolumn{3}{|c|}{ Amount of biotin-vitamer assayed with } & \multirow{2}{*}{$\begin{array}{l}\text { Amount of } \\
\text { BS-factor } \\
(\mathrm{B})-(\mathrm{A}) \\
(\mu \mathrm{g} / \mathrm{ml})\end{array}$} & \multirow{2}{*}{$\begin{array}{l}\text { Dry weigh } \\
\text { of } \mathrm{myceliur} \\
(\mathrm{mg} / 5 \mathrm{ml}\end{array}$} \\
\hline & & & $\begin{array}{l}\text { L. arab. } \\
(\mathrm{m} \mu \mathrm{g} / \mathrm{ml})\end{array}$ & $\begin{array}{l}\text { S. cerev. (A) } \\
(\mu \mathrm{g} / \mathrm{ml})\end{array}$ & $\underset{(\mu \mathrm{g} / \mathrm{ml})}{\text { B. }}$ & & \\
\hline \multirow{3}{*}{ Urea } & + & - & 75 & 11 & 11 & 0 & 70 \\
\hline & $\overline{+}$ & $\overline{+}$ & $\begin{array}{r}0 \\
55\end{array}$ & trace & trace & 0 & 60 \\
\hline & \pm & + & $\begin{array}{r}33 \\
0\end{array}$ & $\begin{array}{c}t \\
\text { trace }\end{array}$ & $\begin{array}{c}6 \\
\operatorname{trace}\end{array}$ & $\begin{array}{l}2 \\
0\end{array}$ & $\begin{array}{l}60 \\
60\end{array}$ \\
\hline \multirow{3}{*}{$\mathrm{NH}_{4} \mathrm{Cl}$} & + & - & 0 & $\begin{array}{c}\text { trace } \\
9\end{array}$ & $\begin{array}{c}\text { trace } \\
10\end{array}$ & 1 & $\begin{array}{l}60 \\
23\end{array}$ \\
\hline & - & - & 0 & trace & $\begin{array}{l}10 \\
\text { trace }\end{array}$ & 0 & $\begin{array}{l}23 \\
25\end{array}$ \\
\hline & + & + & 10 & 7 & 10 & 3 & 25 \\
\hline \multirow{4}{*}{$\left(\mathrm{NH}_{4}\right)_{2} \mathrm{SO}_{4}$} & - & + & 0 & trace & trace & 0 & 31 \\
\hline & + & - & $\begin{array}{l}5 \\
0\end{array}$ & 7 & 8 & 1 & 40 \\
\hline & $\bar{t}$ & $\bar{t}$ & $\begin{array}{l}0 \\
5\end{array}$ & & $\begin{array}{l}\text { trace } \\
8\end{array}$ & 0 & $\begin{array}{l}45 \\
45\end{array}$ \\
\hline & \pm & + & 0 & $\begin{array}{c}8 \\
\text { trace }\end{array}$ & $\begin{array}{c}8 \\
\text { trace }\end{array}$ & $\begin{array}{l}0 \\
0\end{array}$ & $\begin{array}{l}45 \\
45\end{array}$ \\
\hline \multirow{3}{*}{$\mathrm{NH}_{4} \mathrm{NO}_{3}$} & + & - & 0 & 10 & 10 & 0 & $\begin{array}{l} \pm 0 \\
35\end{array}$ \\
\hline & - & - & 0 & trace & tracel & 0 & 40 \\
\hline & + & + & 5 & 10 & 10 & 0 & 40 \\
\hline \multirow{4}{*}{$\mathrm{NaNO}_{3}$} & - & + & 0 & trace & trace & 0 & 35 \\
\hline & + & - & 100 & 10 & 10 & 0 & 60 \\
\hline & $\bar{t}$ & $\overline{+}$ & $\begin{array}{r}0 \\
30\end{array}$ & $\begin{array}{l}\text { trace } \\
\text { trace }\end{array}$ & $\begin{array}{c}\text { trace } \\
4\end{array}$ & $\begin{array}{l}0 \\
4\end{array}$ & $\begin{array}{l}55 \\
45\end{array}$ \\
\hline & - & + & 0 & $\begin{array}{l}\text { trace } \\
\text { trace }\end{array}$ & $\begin{array}{c}4 \\
\text { trace }\end{array}$ & $\begin{array}{l}4 \\
0\end{array}$ & $\begin{array}{l}45 \\
45\end{array}$ \\
\hline \multirow{4}{*}{$\begin{array}{l}\text { Casamino } \\
\text { acid }\end{array}$} & + & - & 90 & 5 & 8 & 3 & $\begin{array}{l}45 \\
75\end{array}$ \\
\hline & - & - & 10 & trace & trace & 0 & $\begin{array}{l}75 \\
70\end{array}$ \\
\hline & + & + & 30 & trace & 6 & 6 & $\begin{array}{l}70 \\
70\end{array}$ \\
\hline & - & + & 0 & trace & trace & 0 & $\begin{array}{l}10 \\
65\end{array}$ \\
\hline \multirow{4}{*}{ Peptone } & + & - & 25 & trace & 5 & 5 & 80 \\
\hline & - & - & 0 & trace & trace & 0 & 65 \\
\hline & \pm & $\begin{array}{l}+ \\
+\end{array}$ & 30 & trace & 5 & 5 & 70 \\
\hline & - & + & 0 & trace & trace & 0 & 80 \\
\hline
\end{tabular}

* Concentration of metal jons was the same as described in the text. 
metal ions, relatively large amount of true biotin was produced, but both biotin activities for the growths of Saccharomyces cerevisiae and Bacillus subtilis were nearly equal. Therefore, it was assumed that BS-factor was hardly produced under the conditions. On the other hand, when sodium nitrate or casamino acid was used as nitrogen source with addition of metal ions, biotin activity assayed with Saccharomyces cerevisiae scarcely remained in the culture medium, but that assayed with Bacillus subtilis remained about 40 to 50 per cent to initial activity. The result showed that desthiobiotin added was converted to BSfactor. When peptone was used as a nitrogen source, desthiobiotin added was converted to BS-factor without the addition of metal ions. These results suggest that desthiobiotin was converted to BS-factor by the mold. Some metal ions were necessary for the conversion reaction of desthiobiotin to BS-factor. However, it was uncertain which metal ion was effective.

Time Course of the Production of Biotin and BS-Factor from Desthiobiotin

As shown in Fig. 2, the production of true biotin reached maximum at 3 days of the culture, while it was continually decreased along with the culture days. On the other hand, both biotin activities in the culture medium for the growths of Saccharomyces

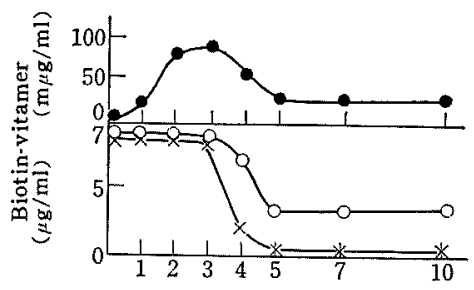

Cultivation time (days)

FIG. 2. The Time Course of the Production of Biotin and BS-Factor from Desthiobiotin by Aspergillus oryzae.

$=$ : Biotin activity assayed with $L$. arabinosus

$-x-$ : Biotin activity assayed with $S$. cerevisiae cerevisiae and Bacillus subtilis were nearly equal at early days of the culture. Therefore, desthiobiotin added was not changed to BSfactor at the early days of the culture. However, the biotin activity for the growth of Saccharomyces cerevisiae was remarkably decreased along with the culture days, whereas the biotin activity for the growth of Bacillus subtilis remained about 40 to 50 per cent to initial activity.

In order to clarify the characteristics of the degradation product of desthiobiotin, biotinvitamers in the culture medium were analyzed by anion-exchange column chromatography. The results are shown in Fig. 3 ( $\mathrm{a}$ and $\mathrm{b}$ ). As shown in Fig. 3 (a) at the early stage of the growth (2 days-culture), desthiobiotin (fraction C) which was added to the medium prior to the cultivation almost remained without further metabolic alteration, although a small amount of BS-factor (fraction B) was observed. On the other hand, as shown in Fig. $3(\mathrm{~b})$, at the long-term cultivation ( 7 days-culture), desthiobiotin added almost completely vanished and a large amount of BS-factor (fraction B) was observed. These results showed that, at the early stage of the growth, desthiobiotin added

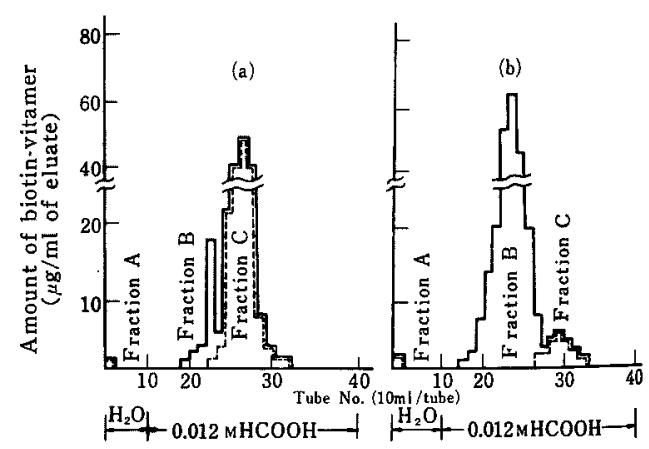

FIG. 3. Ion-Exchange Analysis of Biotin-Vitamers in the Culture Filtrate of Aspergillus oryzae.

\footnotetext{
Exchanger: Dowex-1×2 (formate), 200 400 mesh

Volume of resin: $1 \mathrm{~cm} \times 19 \mathrm{~cm}$

Flow rate: $1.5 \mathrm{ml}$ per minute

--: : Assayed with Saccharomyces cerevisiae

- : Assayed with Bacillus subtilis

(a): 2 days-culture, (b): 7 days-culture
} 
was partly changed to true biotin and BSfactor, and that, when the mold was cultivated for a long term, desthiobiotin added was almost completely converted to BS-factor.

Effect of Desthiobiotin Concentration on the Production of BS-Factor

When 10 to $1000 \mu \mathrm{g}$ of $d, l$-desthiobiotin per mere added to the medium, as shown in Table III, desthiobiotin was almost completely converted to BS-factor and the amount of BSfactor produced was almost in proportion to desthiobiotin concentration added. When $5 \mathrm{mg}$ of desthiobiotin per $\mathrm{ml}$ was added, desthiobiotin was partly converted to BS-factor, but considerable amount of desthiobiotin remained.

Table III. EFfect of Desthiobiotin ConcenTRATIONS ON THE PRODUCTION OF BIOTIN AND BS-FACTOR (7 days-culture)

\begin{tabular}{|c|c|c|c|c|}
\hline \multirow{2}{*}{$\begin{array}{l}d l- \\
\text { Desthio- } \\
\text { biotin } \\
\text { added } \\
(\mu \mathrm{g} / \mathrm{ml})\end{array}$} & \multicolumn{3}{|c|}{$\begin{array}{l}\text { Amount of biotin-vitamer } \\
\text { assayed with }\end{array}$} & \multirow{2}{*}{$\begin{array}{c}\text { Amount of } \\
\text { BS-factor } \\
(\mathrm{B})-(\mathrm{A}) \\
(\mu \mathrm{g} / \mathrm{ml})\end{array}$} \\
\hline & $\begin{array}{l}\text { L. arab. } \\
(\mathrm{m} \mu \mathrm{g} / \mathrm{ml})\end{array}$ & $\begin{array}{l}\text { S. cerev. (A) } \\
(\mu \mathrm{g} / \mathrm{ml})\end{array}$ & $\begin{array}{l}\text { B. sub. (B) } \\
(\mu \mathrm{g} / \mathrm{ml})\end{array}$ & \\
\hline 0 & 0 & trace & trace & trace \\
\hline 10 & 10 & $"$ & 2 & 2 \\
\hline 100 & 10 & $n$ & 32 & 32 \\
\hline 1000 & 35 & 3 & 400 & 397 \\
\hline 5000 & 80 & 500 & 2300 & 1800 \\
\hline
\end{tabular}

Crystallization of BS-Factor from Culture Filtrate of Aspergillus oryzae

Aspergillus oryzae which has intensive ability to produce BS-factor from desthiobiotin was grown for 10 days with continuous shaking (130 reciprocations per minute) in $2000 \mathrm{ml}$ of the medium containing $1.5 \mathrm{~g}$ of $d, l$-desthiobiotin. After the growth, the cultures were filtered through the filter paper to remove the mycelial mats. Purification of the BS-factor was carried out by following procedures: the $\mathrm{pH}$ of the culture filtrate was adjusted to 2 with hydrochloric acid solution. Biotinvitamers were adsorbed on $40 \mathrm{~g}$ of active carbon at room temperature and the active carbon was collected on a Büchner funnel and washed with about $100 \mathrm{ml}$ of water. Biotinvitamers were eluted from the active carbon with about $500 \mathrm{ml}$ of the ethanol-ammonia mixture (prepared by mixing 9 parts of 50 per cent ethanol and 1 part of 28 per cent ammonia water). The eluate was concentrated to syrup in vacuo at the temperature of below $50^{\circ} \mathrm{C}$, and the biotin-vitamers were extracted with $100 \mathrm{ml}$ of 75 per cent ethanol and the extract was again concentrated to about $30 \mathrm{ml}$ under the reduced pressure. The concentrate was taken onto Dowex- $50\left(\mathrm{H}^{+}\right)$column $(30 \mathrm{~mm}$ $\times 150 \mathrm{~mm}$ ). The biotin-vitamers were washed out with $1000 \mathrm{ml}$ of deionized water from the column. The washings were concentrated to about $30 \mathrm{ml}$ in vacuo at below $50^{\circ} \mathrm{C}$. The concentrate was placed onto Dowex-1 $\times 2$ formate column $(28 \mathrm{~mm} \times 300 \mathrm{~mm})$, and then the column was washed with $500 \mathrm{ml}$ of water. The BS-factor and other biotin-vitamers were eluted with $0.01 \mathrm{~m}$ formic acid and fractions of $50 \mathrm{ml}$ were collected. The contents of biotin-vitamers in each fraction were quantitatively determined by microbiological assays with using Saccharomyces cerevisiae, Bacillus subtilis and Lactobacillus arabinosus, respectively. The eluate fractions which showed biotin activity only for Bacillus subtilis were concentrated to about $10 \mathrm{ml}$. The concentrate was allowed to stand overnight at $0^{\circ} \mathrm{C}$. The crude crystal formed was collected. About $500 \mathrm{mg}$ of the crystal was obtained. After recrystallization from minimum amount of 70 per cent ethanol, $300 \mathrm{mg}$ of pure crystal was obtained. This pure crystal was subjected to the following analysis.

Some Chromatographic Characteristics of the Compound

In order to clarify the characteristics of the compound, some chromatographic properties of the compound were investigated. As shown in Table IV, the $R_{F}$ values of the compound with several solvent systems were similar to those of authentic biotin. As shown in Table $\mathrm{V}$, the mobilities of the compound were similar to those of authentic desthiobiotin over all $\mathrm{pH}$ ranges tested. Microbiological activity of the compound was investigated with various 
TABLE IV. $R_{F}$ Values of the Compound

\begin{tabular}{|c|c|c|c|}
\hline \multirow[b]{2}{*}{ Solvent system } & \multicolumn{3}{|c|}{$R_{F}$ value } \\
\hline & Biotin & $\begin{array}{l}\text { Desthio- } \\
\text { biotin }\end{array}$ & $\begin{array}{l}\text { BS- } \\
\text { factor }\end{array}$ \\
\hline $\begin{array}{l}n \text {-Butanol-acetic acid-water } \\
\quad(4: 1: 1)\end{array}$ & 0.86 & 0.90 & 0.82 \\
\hline$n$-Butanol-1 N HCl $(6: 1)$ & 0.59 & 0.70 & 0.61 \\
\hline$n$-Butanol (satd. with water) & 0.81 & 0.87 & 0.78 \\
\hline Phenol-water $(4: 1)$ & 0.97 & 0.94 & 0.94 \\
\hline
\end{tabular}

TABle V. Paper ElEctrophoresis of the COMPOUND

\begin{tabular}{cccc} 
& \multicolumn{3}{c}{ Mobility $(\mathrm{cm})$} \\
2 & Biotin & Desthiobiotin & BS-factor \\
3 & 0 & -0.7 & -0.8 \\
4 & +1.0 & -1.2 & -1.4 \\
5 & +1.4 & +0.7 & +1.2 \\
6 & +2.7 & +3.3 & +3.0 \\
7 & +2.5 & +3.0 & +2.9 \\
8 & +3.4 & +3.5 & +3.9 \\
& +3.2 & +3.1 & +3.9
\end{tabular}

Table VI. Microbiological ACtivity of the COMPOUND

$\begin{array}{lc}\text { Microorganisms } & \text { Biotin activity* }(\%) \\ \text { Bacillus subtilis } & 40 \quad \sim 60 \\ \text { Saccharomyces cerevisiae } & 0.04 \sim 0.06 \\ \text { Neurospora crassa } & 0.05 \sim 0.2 \\ \text { Lactobacillus arabinosus } & 0.002 \sim 0.004 \\ \text {-biotin }=100 . & \end{array}$

biotin-requiring microorganisms. As shown in Table VI, the compound hardly supported the growth of Saccharomyces cerevisiae, Lactobacillus arabinosus and Neurospora crassa, however, it had the same activity with $d, l$-desthiobiotin for the growth of Bacillus subtilis. From these data, it was found that, although chromatographic properties of the compound were closely similar to those of desthiobiotin or biotin, microbiologicol spectra were quite different from desthiobiotin and biotin.

\section{Chemical Structure of the Compound}

The elemental analysis of the compound supported the molecular formula $\left(\mathrm{C}_{3} \mathrm{H}_{14} \mathrm{O}_{3} \mathrm{~N}_{2}\right)$ in which $\mathrm{C}_{2} \mathrm{H}_{4}$ was released from desthiobiotin. Anal. Found: C, $51.57 \% ; \mathrm{H}, 7.67 \% ; \mathrm{N}, 14.85 \%$. Calcd. For $\mathrm{C}_{8} \mathrm{H}_{14} \mathrm{O}_{3} \mathrm{~N}_{2}: \mathrm{C}, 51.60 \% ; \mathrm{H}, 7.58 \%$; N, $15.05 \%$.
Infrared spectrum of the compound suggests that the compound had the similar structure to desthiobiotin: $\nu_{\mathrm{COOH}}=1710,3200 \sim 2500 \mathrm{~cm}^{-1}$ (broad), $\nu_{\mathrm{CO}-\mathrm{NH}}=3300,1660 \mathrm{~cm}^{-1}$.

On the other hand, NMR spectrum of the compound in heavy water showed a doublet $(3 \mathrm{H})$ at $\tau=8.9$ p.p.m. for the methyl protons, a multiplet $(4 \mathrm{H})$ centered at 8.4 p.p.m. for four protons of two methylene groups, a multiplet $(2 \mathrm{H})$ centered at 7.6 p.p.m. for methylene protons being adjacent to the carboxyl group, and a multiplet $(2 \mathrm{H})$ centered at 6.1 p.p.m. for two methenyl protons in the ureido ring.

The melting point $\left(140 \sim 141^{\circ} \mathrm{C}\right)$ of the compound was identical with 4-methyl-5-( $\omega$ carboxybutyl)-imidazolidone-2 which had been synthesized by Duschinsky and Dolan. ${ }^{91}$

From these data, the following chemical structure in which $\mathrm{C}_{2} \mathrm{H}_{4}$ was released from desthiobiotin was given to the BS-factor:

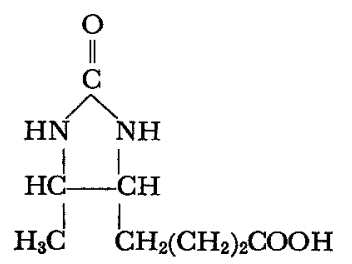

The crystalline material had no optical rotation, suggesting that both $d$ - and $l$-form of desthiobiotin were nonspecifically converted to the compound.

The same compound was already chemically synthesized in 1945 by Duschinsky and Dolan, ${ }^{9}$ however, it had not been known that such a compound was produced from desthiobiotin by microorganisms, and that the compound was utilized by biotin-requiring microorganisms as a sparing substance of biotin. Although the mechanism of the reaction is not clear, perhaps, the compound was produced by $\beta$ oxidation of the side chain of the desthiobiotin. The mechanism of the reaction is under investigation.

9) R. Duschinsky and L. A. Dolan, J. Am. Chem. Soc., 67, 2079 (1945). 
Acknowledgement. The authors express their sincere thanks to Professor M. Nakazima and Assistant Professor K. Fukami of Kyoto University for the infrared and NMR analyses and their useful discussion during the course of this investigation, and they also indebted to Professor T. Mitui of Kyoto University for the elemental analysis. Thanks are also due to Assistant Professor H. Yamada, Research Institute for Food Science of Kyoto University, for his advice during the course of this work. 